\title{
Catalytic hydrogen transfer over magnesia. Part XXV. Liquid and vapor phase reduction of ketoesters
}

\author{
M. Gliński • A. Czajka • U. Ulkowska
}

Received: 29 July 2014/ Accepted: 8 September 2014/Published online: 1 October 2014

(C) The Author(s) 2014. This article is published with open access at Springerlink.com

\begin{abstract}
The reactivity of two series of compounds: alkyl x-oxoalkanoates $(\mathrm{x}=2,3,4$ and 6), and alkyl $\omega$-phenyl-y-oxoalkanoates $(\mathrm{y}=2$ and 4 ) has been studied in the catalytic transfer hydrogenation (CTH) over magnesium oxide as the catalyst. The catalytic tests have been performed either in liquid or vapor phase with secondary alcohols (2-propanol to 2-octanol) as hydrogen donors. A strong diminution of reactivity of the ketoesters in $\mathrm{CTH}$ has been observed, in contrast to simple aliphatic or aralkyl ketones. The occurrence of transalcoholysis between ketoesters and alcohols used as hydrogen donors resulted in the formation of new ketoesters as side products. The hydroxoesters, i.e. the products of the CTH reaction, have been obtained with only moderate to good yields (up to $50 \%$ ). It has been found that in the $\mathrm{CTH}$ of ketoesters with the carbonyl group in a $\gamma$ position, such as alkyl levulinates and benzoylpropionates, the appropriate lactones ( $\gamma$-valerolactone and 5-phenyl- $\gamma$-valerolactone) have been formed.
\end{abstract}

Keywords Transfer hydrogenation - Ketoesters · Magnesium oxide $\cdot$ Lactones

\section{Introduction}

Catalytic hydrogen transfer, also known as catalytic transfer hydrogenation (CTH), is a useful method for the reduction of many aldehydes and ketones to the corresponding alcohols under mild conditions [1,2]. This reduction can be

Part XXIV-Gliński M, Ulkowska U (2011) Catal Lett 141:293-299.

M. Gliński $(\bowtie) \cdot$ A. Czajka · U. Ulkowska

Faculty of Chemistry, Chair of Chemical Technology, Warsaw University of Technology

(Politechnika), Noakowskiego 3, Warsaw 00-664, Poland

e-mail: marekg@ch.pw.edu.pl 
performed either in vapor or liquid phase, depending on the acceptor reactivity, with alcohols as hydrogen donors. What is also very important is that it does not require any special equipment due to the lack of hydrogen gas and operation under atmospheric pressure. Metal oxides, such as $\mathrm{MgO}$ [3-6], $\mathrm{Al}_{2} \mathrm{O}_{3}$ [7], $\mathrm{ZrO}_{2} \cdot \mathrm{nH}_{2} \mathrm{O}$ [8-10], as well as mixtures of two or three metal oxides [11-14], magnesium phosphates [15] and zeolites [16-18] have been used as catalysts. Recently, the catalysts obtained from hydrotalcites have also been used in CTH [12, 19-21]. According to the published works, $\mathrm{MgO}$ is one of the most efficient oxide catalysts in the $\mathrm{CTH}$ of carbonyl compounds with alcohols $[1,2]$.

Various carbonyl compounds have been studied as hydrogen acceptors in the $\mathrm{CTH}$ in the presence of magnesium oxide. The reactivity of aliphatic straightchained ketones with short and long alkyl chains [5, 22], the latter with a carbonyl group which occupies all the positions along the carbon chain [5], branched ketones with alkyl or cycloalkyl groups of different bulkiness [5] in CTH have been determined. Various cycloalkanones, from cyclopentanone up to cyclopentadecanone have been used as hydrogen acceptors [23, 24]. The unprecedented diastereoselectivity of $\mathrm{MgO}(\geq 98 \%)$ has been shown by us in the liquid phase CTH of 4-t-butylcyclohexanone with secondary alcohols [6]. A comprehensive study of the reactivity of a series of mono-, di- and trisubstituted aralkyl ketones in $\mathrm{CTH}$ over $\mathrm{MgO}$, either in vapor or liquid phase, has been published recently [4].

The CTH is also known as a chemoselective reduction method of $\alpha, \beta-$ unsaturated carbonyl compounds into unsaturated alcohols [20, 25-28]. It is well known that the hydrogenation of these carbonyl compounds with gaseous hydrogen under pressure in the presence of the majority of metallic catalysts leads to the formation of only saturated carbonyl compounds (aldehyde/ketones) or saturated alcohols as the main products.

Ketoesters are organic compounds containing two functional groups with quite different reducibility. The presence of the prochiral carbonyl group in their molecules focuses attention of many chemists due to the stereochemical aspects of its asymmetric hydrogenation in the presence of metallic catalysts modified by various chiral auxiliaries [29, 30]. Although the CTH of various carbonyl compounds has been studied systematically since the 1970s, the reduction of ketoesters by this method has remained unexplored until almost the present day. Recently, only esters of levulinic acid, the products of the hydrolysis of lignocellulosic materials treated as renewable biomass, have been used as hydrogen acceptors. $\gamma$-Valerolactone (GVL), the product of their transformations has been obtained using formic acid as a hydrogen source in the presence of noble metals $(\mathrm{Ru}, \mathrm{Au})[31,32]$ or using secondary alcohols as hydrogen donors in the presence of metal oxides as catalysts [33]. It has been reported that among metal oxides such as $\mathrm{MgO} / \mathrm{Al}_{2} \mathrm{O}_{3}, \mathrm{MgO} / \mathrm{ZrO}_{2}, \mathrm{CeO}_{2} / \mathrm{ZrO}_{2}$, $\mathrm{Al}_{2} \mathrm{O}_{3}$ and $\mathrm{ZrO}_{2}$, the last oxide has shown the highest activity in the liquid phase transfer hydrogenation of alkyl levulinates at $423 \mathrm{~K}$ performed under $2.1 \mathrm{MPa}$ pressure [33]. Until now, neither the activity of pure $\mathrm{MgO}$ in the CTH of ketoesters has been measured nor systematic studies of the CTH of various ketoesters with alcohols as hydrogen donors have been undertaken. Herein, we report the activity of $\mathrm{MgO}$ in liquid and vapor phase transfer hydrogenation of two series of ketoesters with a set of 
secondary alcohols as hydrogen donors, as a continuation of our studies on the use of magnesium oxide as a catalyst in the $\mathrm{CTH}$ of carbonyl compounds.

\section{Experimental}

Catalyst synthesis and characterization

Magnesium oxide was prepared by the thermal decomposition of $\operatorname{Mg}(\mathrm{OH})_{2}$ $(0.16-0.40 \mathrm{~mm}$ grain diameter) at $873 \mathrm{~K}$ for $1 \mathrm{~h}$ in a stream of dry air and for $5 \mathrm{~h}$ in a stream of dry deoxygenated nitrogen. The details of its preparation are described elsewhere [28].

Magnesium oxide was characterized by a number of techniques, such as: XRD (powder diffraction patterns were obtained on a D-5000 Siemens diffractometer with Ni-filtered $\mathrm{CuK}_{\alpha}$ radiation), TG-DTA (NETZSCH STA 449 thermobalance, heating ramp $10 \mathrm{~K} \mathrm{~min}^{-1}$ in Ar flow) and nitrogen physisorption (Micromeritics ASAP 2020). The concentrations of acidic and basic sites were measured using titration (with solutions of $n$-butylamine, triethylamine, and benzoic acid). The strength of acidic and basic sites was measured using Hammett's indicators, according to the procedure described elsewhere [34].

\section{Hydrogen acceptors (Scheme 1)}

Ethyl esters of the following acids: pyruvic (1), acetoacetic (2), and benzoylformic (5) acids were supplied by Aldrich. Alkyl esters of levulinic acid (2-propyl (3a), $n$ butyl (3b) and 2-octyl (3c)) were prepared by direct esterification of levulinic acid (98\%, Aldrich) with the appropriate alcohols in toluene as a solvent, in the presence small amounts of $p$-toluenesulfonic acid. 6-Oxoheptanoic acid was prepared by oxidation of 2-methylcyclohexanone according to the procedure described in literature [35]. Its 2-propyl ester (4) was prepared in the same manner as the esters of levulinic acid. Benzoylpropionic acid was prepared by acylation of benzene with succinic anhydride in the presence of anhydrous aluminum chloride as the catalyst [36]. Its 2-propyl ester (6) was synthesized in direct esterification in toluene as a solvent in the presence of $p$-toluenesulfonic acid as the catalyst. All esters were purified by fractional distillation under reduced pressure, the purities of the middle fractions exceeded $99 \%$ (GC).

2-Undecanone (7) (methyl $n$-nonyl ketone) (99\%, Aldrich) and valerophenone (8) (1-phenyl-1-pentanone) (98\%, Aldrich) were distilled under reduced pressure Scheme 2.

\section{Hydrogen donors}

2-Propanol (p.a., POCh Gliwice, Poland), 2-butanol (99.5 \%, Ubichem, England) and 2-pentanol (98\%, Aldrich) were distilled under normal pressure over metallic potassium in dry nitrogen atmosphere and were stored over dried molecular sieves (3 $\AA$ ) in Schlenk-type containers. 2-Octanol (97\%, Aldrich) was distilled under 

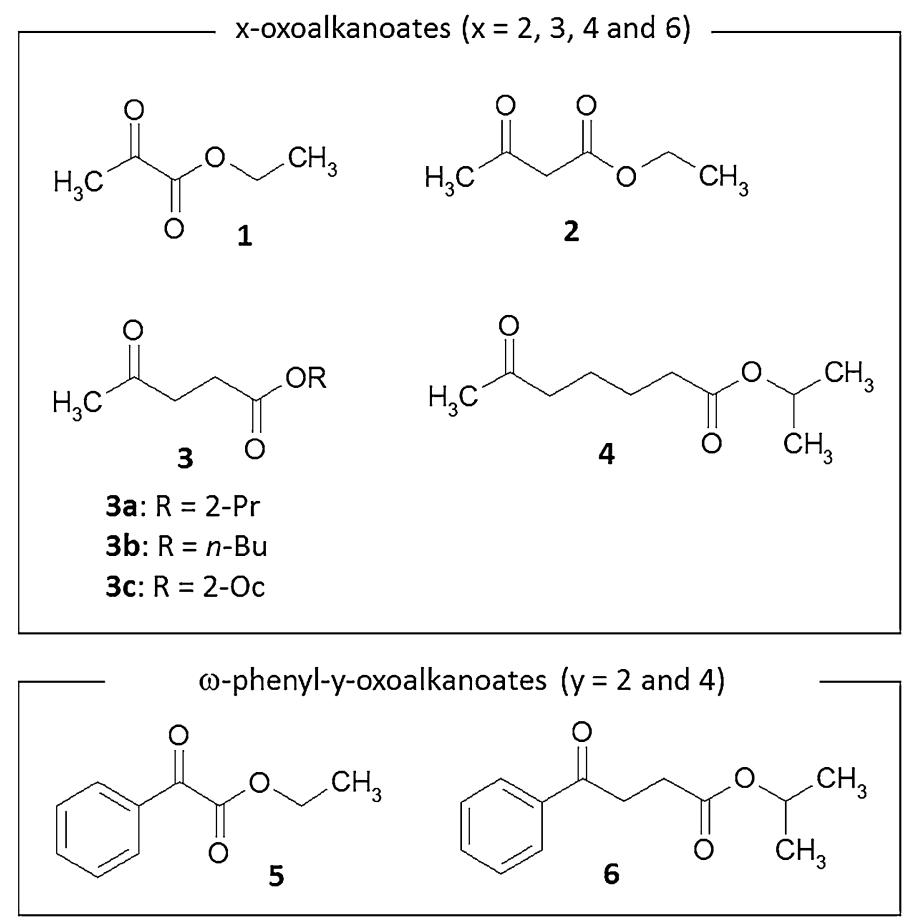

Scheme 1 Ketoesters used as hydrogen acceptors<smiles>CCCCCCCCCC(C)=O</smiles><smiles>CCCCC(=O)c1ccccc1</smiles>

Scheme 2 Ketones used as hydrogen acceptors

reduced pressure through a $50 \mathrm{~cm}$ long vacuum jacketed Vigreux column and the middle fraction with a purity of $98.8 \%$ (GC) was used for catalytic tests.

Other reactants

Benzoic acid (99\%, Aldrich) was purified by sublimation under reduced pressure. $n$-Butylamine and triethylamine (99 \%, both Aldrich) were dried over $\mathrm{KOH}$ pellets for 2 weeks and distilled over metallic potassium in the atmosphere of nitrogen directly to Schlenk-type containers. After preliminary drying by distillation, toluene (pure p.a., POCh Gliwice, Poland) was refluxed with sodium metal and benzophenone in the atmosphere of dry nitrogen and distilled directly to a Schlenk-type container. 
The following set of Hammett indicators has been used (the values of $\mathrm{pK}_{\mathrm{a}}$ or $\mathrm{pK}_{\mathrm{BH}+}$ are given in parentheses): chalcone (-5.6), dicinnamylideneacetone (-3.0), crystal violet (0.8), methyl red (4.8), bromothymol blue (7.2), phenolphthalein (9.3), 2,4-dinitroaniline (15.0), 4-nitroaniline (18.4), diphenylamine (22.3), 4-chloroaniline (26.5) and triphenylmethane (33.0) in the form of $0.1 \%$ solutions in anhydrous toluene.

\section{Catalytic activity measurements}

Catalytic tests in the liquid phase were performed in a one-piece glass apparatus which consists of a flat bottomed cylinder $\left(20 \mathrm{~cm}^{3}\right.$ volume $)$ with a side arm with a screw cap and a condenser connected with a vacuum-nitrogen line. To the reactor, previously equipped with a magnetic bar, a weighed sample of the catalyst (400 $\pm 10 \mathrm{mg}, 1 \mathrm{mmol})$ was introduced in a stream of nitrogen followed by a hydrogen donor $(5,10$ or $20 \mathrm{mmol})$, an ester $(1.25 \mathrm{mmol})$ and $400 \mathrm{mg}$ of an internal standard ( $t$-butylbenzene or 1,3,5-triisopropylbenzene). The reactor was immersed in a hot thermostated oil bath which was placed on the plate of a magnetic stirrer. The boiling point of the stirred mixture was considered the beginning of the reaction. Samples for analysis $\left(\right.$ c.a. $0.10 \mathrm{~cm}^{3}$ ) were taken through the side arm of the reactor after 1, 3 and $6 \mathrm{~h}$ of reaction and centrifuged (20 min, 3,200 rpm) in order to let the suspension of the catalyst settle.

Vapor phase catalytic tests were performed in a tubular glass reactor with a fixed catalyst bed (250 mg MgO, 0.40-0.63 mm grain diameter). A sample of the catalyst was introduced in a stream of nitrogen. A solution of a given ketoester in alcohol, at $\mathrm{D} / \mathrm{A}=4 \mathrm{~mol} / \mathrm{mol}$, was dosed using a microdosing pump with LHSV: $2 \mathrm{~cm}^{3} \mathrm{~g}^{-1} \mathrm{~h}^{-1}$ into a stream of nitrogen $\left(50 \mathrm{~cm}^{3} \mathrm{~min}^{-1}\right)$.

The reaction products were analyzed by GC using HRGC KONIK (Spain) equipped with a TRACER wax capillary column (length $30 \mathrm{~m}, 0.25 \mathrm{~mm}$ i.d.) and a FID detector. For samples collected in vapor phase experiments, $n$-decane and $n$ dodecane were used as internal standards. Compounds were identified by GC-MS (HP-6890 N with mass detector $5973 \mathrm{~N}$ ) and by comparison of the retention times with those of standard samples.

\section{Results and discussion}

\section{Characterization of $\mathrm{MgO}$ catalyst}

High surface area $\mathrm{MgO} \quad\left(\mathrm{S}_{\mathrm{BET}}=99.7 \mathrm{~m}^{2} \mathrm{~g}^{-1}, \quad \mathrm{~V}_{\mathrm{p}}=0.529 \mathrm{~cm}^{3} \mathrm{~g}^{-1} \quad\right.$ and $\mathrm{D}_{\mathrm{p}}=17 \mathrm{~nm}$ ) was prepared by calcination of previously prepared magnesium hydroxide. The TG-DTA analysis has revealed that the weight loss of a sample of $\mathrm{Mg}(\mathrm{OH})_{2}(320-873 \mathrm{~K})$ is $30.41 \%$ (exp), $30.89 \%$ (calc). The periclase structure of the obtained oxide was confirmed by X-ray diffraction (Fig. 1). The acid-base properties of the $\mathrm{MgO}$ are presented in Table 1.

It has been shown that the prepared $\mathrm{MgO}$ is a very strong solid base. Its strongest basic sites fall in the region of superbasicity $\left(\mathrm{H}_{-}>26.5\right)$ according to Tanabe [37]. 


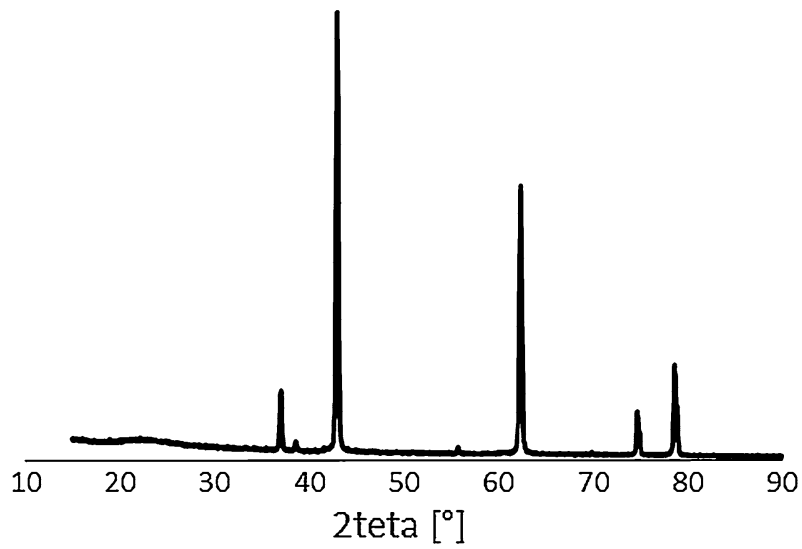

Fig. 1 XRD pattern of prepared $\mathrm{MgO}$

Table 1 Acid-base properties of prepared $\mathrm{MgO}$

\begin{tabular}{lllll}
\hline Acidic sites $\left(\mu \mathrm{mol} \mathrm{g}^{-1}\right)$ & & Basic sites $\left(\mu \mathrm{mol} \mathrm{g}^{-1}\right)$ & $\mathrm{H}_{0}$ & $\mathrm{H}_{-}$ \\
\hline$n-\mathrm{BuNH}_{2}$ & $\mathrm{Et}_{3} \mathrm{~N}$ & & & \\
\hline 115 & 10 & 1,785 & $>4.8$ & $(7.2,33.0)$ \\
\hline
\end{tabular}

Moreover, the concentration of basic sites is also extremely high $\left(1,785 \mu \mathrm{mol} \mathrm{g}^{-1}\right)$. This value is very high in comparison to the ones usually reported in literature. The difference is caused mainly by the fact that benzoic acid is at least 100 times stronger acid than the most popular probe molecule used in TPD measurements $\left(\mathrm{CO}_{2}\right)$.

On the other hand, the strength of acidic sites of $\mathrm{MgO}$ (Brønsted type) as determined by titration with triethylamine is very weak and their concentration is extremely low $\left(\mathrm{Et}_{3} \mathrm{~N}, 10 \mu \mathrm{mol} \mathrm{g}{ }^{-1}\right)$. It was assumed that due to steric demands, triethylamine reacts preferentially with Brønsted type acidic sites. However, the titration of $\mathrm{MgO}$ with $n-\mathrm{BuNH}_{2}$ revealed that the surface of the oxide also contains noticeable concentration of Lewis acidic sites $\left(\sim 100 \mu \mathrm{mol} \mathrm{g}^{-1}\right)$.

Reduction of $\mathrm{CH}_{3} \mathrm{CO}\left(\mathrm{CH}_{2}\right)_{\mathrm{n}} \mathrm{COOR}(\mathrm{n}=0,1,2$ and 4) type ketoesters

Reduction of a ketoester by secondary alcohols, in the presence of $\mathrm{MgO}$ as the catalyst, proceeds according to Scheme 3 .

A hydroxoester and ketone were the products of the main reaction. The high basicity of the catalyst favors the occurrence of side reactions, such as transalcoholysis of the starting ketoester, when its alkyl group is different from the alkyl group in the molecule of the donor (Scheme 4). 
<smiles>[R]OC(=O)CCC(C)(C)C(C)=O</smiles><smiles>[R]OC(=O)CCC(C)C(C)O</smiles>

for $\mathrm{n}$ and $\mathrm{R}$ - see Scheme 1

$1^{\prime}: \mathrm{n}=0, \mathrm{R}=\mathrm{Et}$;

$\mathrm{R}^{\prime}: \mathrm{Me}, \mathrm{Et}, n-\mathrm{Pr}, n-\mathrm{C}_{6} \mathrm{H}_{13}$

2': $n=1, R=E t ;$

3a': $n=2, R=2-P r ;$

$3 \mathbf{b}^{\prime}: \mathrm{n}=2, \mathrm{R}=n-\mathrm{Bu}$

$3 c^{\prime}: n=2, R=2-O c ;$

$4^{\prime}: n=4, R=2-P r$

Scheme 3 CTH of various ketoesters with secondary alcohols<smiles>[R]OC(=O)CCC(C)C(C)=O</smiles>

for $n$ and $\mathrm{R}-$ see Scheme 1

$\mathrm{R}^{\prime}$ : Me, Et, $n-\mathrm{Pr}, n-\mathrm{C}_{6} \mathrm{H}_{13}$<smiles>[R]OC([R])C(=O)OC(C)CCC(C)C(C)=O</smiles>

3d: $\mathrm{n}=2, \mathrm{R}^{\prime}=n-\mathrm{Pr}$;

4a: $\mathrm{n}=4, \mathrm{R}^{\prime}=n-\mathrm{C}_{6} \mathrm{H}_{13}$

(another numbers - see Scheme 1)

Scheme 4 Transalcoholysis reaction

The results clearly show that the reduction of $\gamma$-ketoesters, such as alkyl levulinates, is accompanied by the cyclization of the primary reaction product with the formation of $\gamma$-valerolactone (GVL) (Scheme 5).

The CTH of 2-propyl levulinate (3a) with alcohols results in the formation of

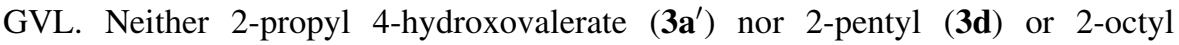
levulinates (3c) were observed among reaction products. A lack of other compounds derived from the starting ester has also been noted. The yields of the GVLs after 1, 3 and $6 \mathrm{~h}$ in transfer hydrogenation of alkyl levulinates (3) three different hydrogen donors and hence three different temperatures are presented in Fig. 2. A strong dependence of the reactivity of 2-propyl levulinate (3a) on temperature has been found (Fig. 2). The order, regardless of the reaction time, was: $355<392<451 \mathrm{~K}$. The differences increase with the reaction time. After $1 \mathrm{~h}$ of operation, only traces of the GVL were found at $355 \mathrm{~K}$, whereas 1 and $2 \%$ yields were noted at 392 and $451 \mathrm{~K}$, respectively. Two hours later, the yields increased slightly and were 2, 3 and $5 \%$. It was observed that the increase of reaction time from 1 to $3 \mathrm{~h}$ was not as big as that between 3 and $6 \mathrm{~h}$. After $6 \mathrm{~h}$ of reaction, the yield of the GVL at $451 \mathrm{~K}$ was almost five times as big as that observed at $392 \mathrm{~K}$ and almost five times that noted at $355 \mathrm{~K}$.

In the case of all three studied temperatures, there is a significant increase of the yield of the desired product in time (Fig. 2). The smallest difference was noted in the case of the lowest temperature, whereas the most pronounced difference was found at $451 \mathrm{~K}$. 
<smiles>[R]OC(=O)CCC(C)O</smiles>

$$
\begin{aligned}
& 3 a^{\prime}: n=2, R=2-P r \\
& 3 b^{\prime}: n=2, R=n-B u \\
& 3 c^{\prime}: n=2, R=2-O c
\end{aligned}
$$

Scheme 5 Cyclization reaction

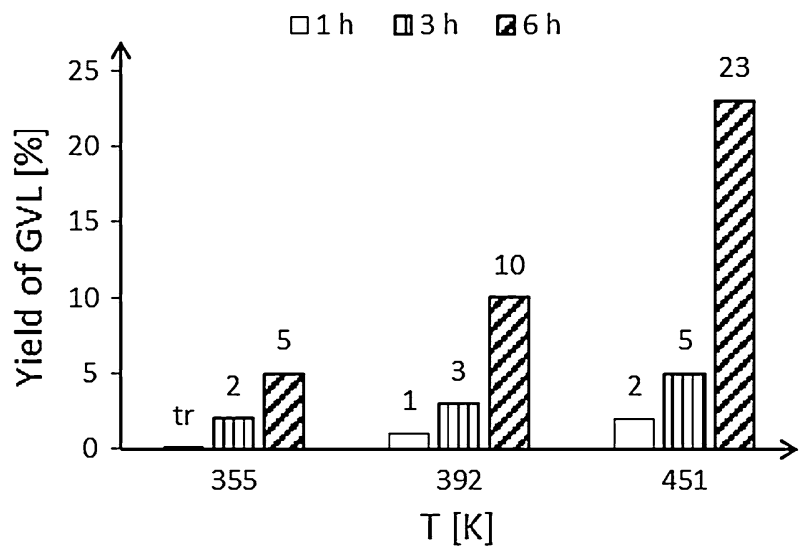

Fig. 2 Influence of the reaction temperature and time of the reaction on the yield of GVL obtained from 2-propyl levulinate (355 K-2-propanol; $392 \mathrm{~K}$-2-pentanol; $451 \mathrm{~K}$-2-octanol)

Studies on the influence of the type of an alkyl group in alkyl levulinates (3) on their reactivity have also been carried out. Their results are shown in Fig. 3. Both levulinates containing secondary alkyl groups (3a and $\mathbf{3 c}$ ) showed higher reactivity than $n$-butyl levulinate (3b). The yields of GVL obtained at the two lower temperatures do no exceed $5 \%$, whereas those obtained at $451 \mathrm{~K}$ are 23,18 and $37 \%$ for 2-propyl levulinate (3a), $n$-butyl levulinate (3b), and 2-octyl levulinate (3c), respectively. The highest difference of yields with the change from 392 to $451 \mathrm{~K}$ was observed for 2-octyl levulinate (3c) and equaled $33 \%$. The elongation of the secondary alkyl group results in a steep increase of the ester's reactivity. For these ketoesters a very high selectivity to GVL (>98\%) has been found, which resembles that for 2-propyl levulinate (3a).

In order to establish how the donor/acceptor ratio impacts the yield of the GVL, the reaction with 2-octyl levulinate (3c) was carried out at three different donor/ acceptor ratios after 1,3 and $6 \mathrm{~h}$ of operation. The studied donor/acceptor ratios were: 4,8 and 16. After all three periods, there was an increase of the yield of the desired product with the increase of the ratio, although the ratio of the yields was different. After $1 \mathrm{~h}$ of reaction with a $\mathrm{D} / \mathrm{A}=4$, the yield was only $3 \%$. It went up by $2 \%$ when the ratio was doubled and again increased by $5 \%$ when the D/A ratio 


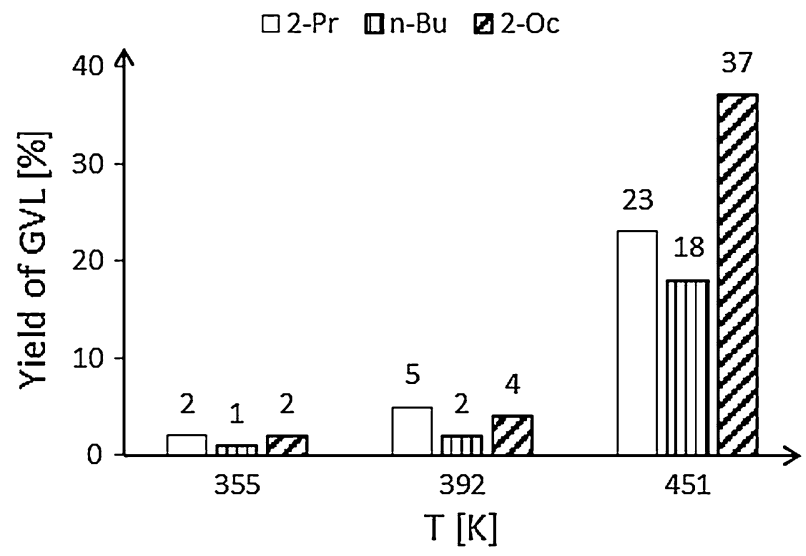

Fig. 3 Influence of alkyl group in the alkyl levulinates on the yield of GVL after $6 \mathrm{~h}$ of the reaction (355 K-2-propanol; $392 \mathrm{~K}$-2-pentanol; $451 \mathrm{~K}$-2-octanol)

reached 16. In the case of the samples taken after $3 \mathrm{~h}$ of reaction, the analysis showed that the GVL yield is 7, 16 and $29 \%$ for D/A $=4,8$, and 16 . In the case of the longest reaction time, namely $6 \mathrm{~h}$, the yields obtained for $\mathrm{D} / \mathrm{A}=4,8$ and 16 were 9,24 and 37. It was noted that after $6 \mathrm{~h}$ of reaction, the decrease of the donoracceptor molar ratio from 16 to 4 leads to a drop of the yield of GVL by $26 \%$ (Fig. 4), which is bigger than those found for the two shorter times.

The results of $\mathrm{CTH}$ of other alkyl ketoesters with the general formula $\mathrm{CH}_{3} \mathrm{CO}\left(\mathrm{CH}_{2}\right)_{\mathrm{n}} \mathrm{COOR}$, where $\mathrm{n}=0,1$ and 4, with 2-pentanol or 2-octanol as hydrogen donors in the presence of $\mathrm{MgO}$ are collected in Table 2. For the first two members of this set of ketoesters, namely ethyl pyruvate (1) and ethyl acetoacetate (2), a fast uptake of these esters with time was observed. Although for pyruvate (1) and acetoacetate (2), conversions as high as 89 and $97 \%$ after $1 \mathrm{~h}$ of reaction were noted, no products were found in liquid mixtures collected during tests. It was shown that the direct reaction between the above-mentioned esters and $\mathrm{MgO}$ occurs with the formation of a salt-like product, which is responsible for their uptake. This type of reaction is caused by the high basicity of the catalyst and secondly by the presence of acidic hydrogen atoms in the molecules of both ketoesters. Indeed, after the introduction of each ketoester into the reactor chamber, a strong coloration of the catalyst together with the changes in its constitution (mud-like appearance) was observed within a short period of time.

In the case of 2-propyl-6-oxoheptanoate (4) transformations, the transalcoholysis of the ester was the main reaction irrespective of the temperature and other reaction conditions (Scheme 6). Yields as high as 58-61\% of 2-octyl 6-oxoheptanoate (4a) were found after $6 \mathrm{~h}$ and were accompanied by much lower yields of the product of the transfer hydrogenation. It has been shown that the increase of the donor/acceptor molar ratio from 8 to 16 causes a steep increase in the yield of 2-octyl 6-hydroxoheptanoate $\left(\mathbf{4} \mathbf{a}^{\prime}\right)$ from 7 to $35 \%$. 


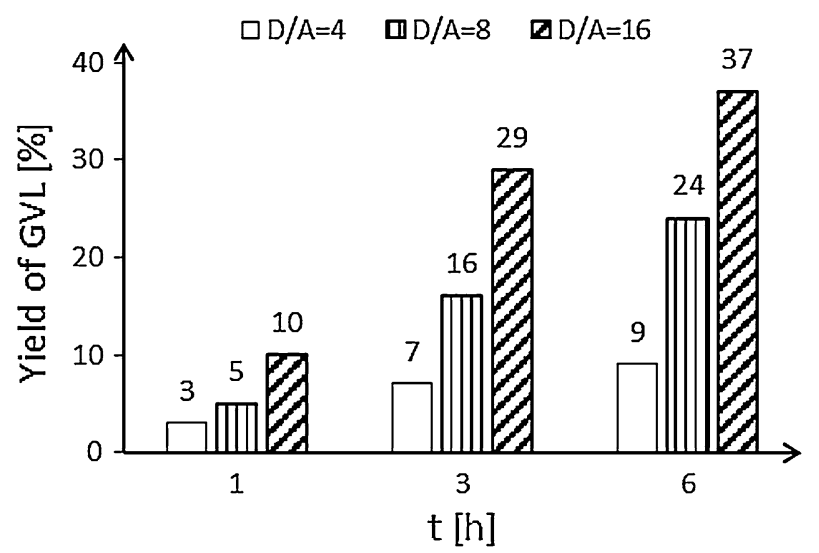

Fig. 4 Influence of donor/acceptor (D/A) molar ratio on the yield of GVL during liquid phase CTH of 2-octyl levulinate with 2-octanol in the presence of $\mathrm{MgO}$

Table 2 Liquid phase transfer hydrogenation of $\mathrm{CH}_{3} \mathrm{CO}\left(\mathrm{CH}_{2}\right)_{n} \mathrm{COOR}(\mathrm{n}=0,1$ and 4) with secondary alcohols in the presence of $\mathrm{MgO}$

\begin{tabular}{|c|c|c|c|c|c|c|}
\hline \multirow[t]{2}{*}{ Acceptor } & \multirow[t]{2}{*}{ Donor } & \multirow[t]{2}{*}{$\mathrm{D} / \mathrm{A}$} & \multirow[t]{2}{*}{$\mathrm{T}_{\mathrm{r}}(\mathrm{K})$} & \multicolumn{3}{|c|}{ Yield of product ${ }^{\mathrm{a}}(\%) /$ Time (h) } \\
\hline & & & & 1 & 3 & 6 \\
\hline \multirow[t]{3}{*}{1} & $2-\mathrm{PeOH}$ & 8 & 392 & - & - & $-{ }^{\mathrm{b}}$ \\
\hline & & 16 & & - & - & $-{ }^{\mathrm{b}}$ \\
\hline & $2-\mathrm{OcOH}$ & 16 & 441 & - & - & $-{ }^{\mathrm{b}}$ \\
\hline \multirow[t]{2}{*}{2} & 2-PeOH & 8 & 392 & - & - & $-{ }^{\mathrm{b}}$ \\
\hline & 2-OcOH & 16 & 451 & - & - & $-^{\mathrm{b}}$ \\
\hline \multirow[t]{3}{*}{$3 \mathbf{a}$} & 2-PeOH & 8 & 392 & $0(0)^{\mathrm{c}}$ & $0(1)^{\mathrm{c}}$ & $0(2)^{\mathrm{c}}$ \\
\hline & 2-OcOH & 8 & 451 & $(5)^{\mathrm{c}} 0^{\mathrm{d}}$ & $(35)^{\mathrm{c}} 4^{\mathrm{d}}$ & $(58)^{\mathrm{c}} 7^{\mathrm{d}}$ \\
\hline & & 16 & & $(25)^{\mathrm{c}} 4^{\mathrm{d}}$ & $(47)^{\mathrm{c}} 20^{\mathrm{d}}$ & $(61)^{\mathrm{c}} 35^{\mathrm{c}}$ \\
\hline
\end{tabular}

\footnotetext{
${ }^{a}$ The appropriate hydroxyesters were formed

b Substrates uptake with time was noted although neither transfer hydrogenation nor transalcoholysis reaction products were observed

${ }^{c}$ In parentheses yields of new oxoesters (products of transalcoholysis) were given

d Yields of 2-octyl 6-hydroxoheptanoate were given
}

\section{Reduction of $\mathrm{PhCO}\left(\mathrm{CH}_{2}\right)_{\mathrm{n}} \mathrm{COOR}(\mathrm{n}=0,2)$ type ketoesters}

The CTH of two representatives from this group of ketoesters, namely ethyl benzoylformate (5) and 2-propyl benzoylpropionate (6), was studied. The results are gathered in Tables 3 and 4. For the former ester (5), three reaction paths have been observed (Scheme 7). First, transfer hydrogenation of a substrate with the formation of ethyl mandelate $\left(\mathbf{5}^{\prime}\right)$; second, the transalcoholysis of a substrate into 2-alkyl benzoylformate $(\mathbf{5 a}, \mathbf{5 b}$ or $\mathbf{5 c})$; and third, subsequent transfer hydrogenation of the primary reaction product-2-alkyl benzoylformate $(\mathbf{5 a}, \mathbf{5 b}$ or $\mathbf{5 c})$ into 2-alkyl 


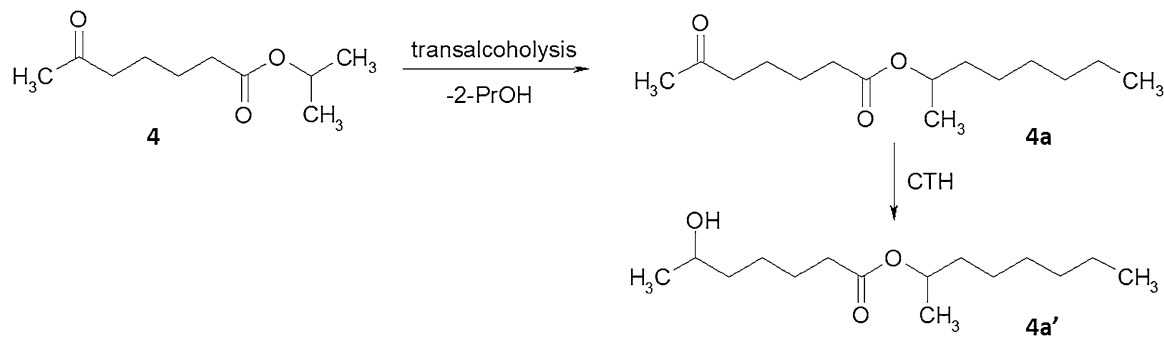

Scheme 6 Transformations of 2-propyl 6-oxoheptanoate (4)

mandelate $\left(\mathbf{5} \mathbf{a}^{\prime}, \mathbf{5} \mathbf{b}^{\prime}\right.$ or $\left.\mathbf{5} \mathbf{c}^{\prime}\right)$. It has been found that the main reaction path is the transalcoholysis of the ketoester, which is followed by subsequent transfer hydrogenation of the primary reaction product. High yields of 2-alkyl benzoylformates (5a, 5b or 5c), up to $81 \%$, were noted. Moreover, an increase in the reaction temperature causes higher yields of 2-alkyl mandelate $\left(\mathbf{5} \mathbf{a}^{\prime}, \mathbf{5} \mathbf{b}^{\prime}\right.$ or $\left.\mathbf{5 c}^{\prime}\right)$ at the expense of the yield of 2-alkyl benzoylformate (5a, $\mathbf{5 b}$ or $\mathbf{5 c}$ ). At $451 \mathrm{~K}$, a $50 \%$ yield of the former product and a $45 \%$ yield of the latter were reached after $6 \mathrm{~h}$ of reaction. The direct transfer hydrogenation of ethyl benzoylformate (5) leads to low yields of ethyl mandelate $\left(\mathbf{5}^{\prime}\right)(<7 \%)$ only.

It was shown that during the CTH of 2-propyl benzoylpropionate (6), the ketoester underwent the same transformations as it was observed in the case of 2-propyl levulinate (3a, Scheme 5). In accordance with this statement, the formation of 5-phenyl- $\gamma$-valerolactone (5-Ph-GVL) as the only product was noted (Scheme 8).

Neither 2-alkyl benzoylpropionates $(\mathbf{6}, \mathbf{6 a}, \mathbf{6 b}$ or $\mathbf{6 c}$ ) nor 2-propyl 4-phenyl-4hydroxobutyrate $\left(\mathbf{6}^{\prime}\right)$ were found in the reaction mixtures. The absence of the latter is caused by its spontaneous transformation into 5-Ph-GVL.

Comparing the reactivity of both ketoesters ( 3 and $\mathbf{6})$ in $\mathrm{CTH}$, for which the formation of lactones has been observed, one can state that the phenyl derivative is more reactive. For this ester as the substrate, yields of 5-Ph-GVL as high as $64 \%$ were reached.

For vapor phase measurements, two ketoesters for which transfer hydrogenation leads to the formation of lactones were chosen (Figs. 5 and 6). In the case of 2-propyl levulinate (3a) as the hydrogen acceptor, two reaction paths were observed. In the first one, the elimination of 2-propanol leads to the formation of isomeric $\alpha$ - (9) and $\beta$-angelica (10) lactones according to the equation presented in Scheme 9. In the second path the transfer hydrogenation of the ketoester into hydroxoester leads to the formation of GVL according to Scheme 5.

It was observed that angelica lactones were the dominating products regardless of the reaction temperature $(573-673 \mathrm{~K})$. At the highest temperature, the yield of GVL did not exceed $7 \%$.

Low yields of 5-Ph-GVL $(<9 \%)$ were noted in the $\mathrm{CTH}$ of 2-propyl benzoylpropionate (6) with 2-propanol as the hydrogen donor. Only a slight increase of the yield of the lactone with reaction temperature has been observed.

Additional studies were undertaken to compare the reactivity of the studied ketoesters with the reactivity shown by aliphatic and aralkyl ketones in transfer 
Table 3 Liquid phase transfer hydrogenation of ethyl benzoylformate (5) with secondary alcohols in the presence of $\mathrm{MgO}$

\begin{tabular}{lllll}
\hline Donor & $\mathrm{T}_{\mathrm{r}}(\mathrm{K})$ & \multicolumn{4}{l}{ Yield of product ${ }^{\mathrm{a}}(\%) /$ Time $(\mathrm{h})$} & 6 \\
\cline { 3 - 5 } & & 1 & 3 & $6(66) 19$ \\
\hline $2-\mathrm{BuOH}$ & 373 & $2(81) 0$ & $6(73) 10$ & $1(72) 24$ \\
$2-\mathrm{PeOH}$ & 392 & $0(80) 2$ & $3(81) 13$ & $4(45) 50$ \\
$2-\mathrm{OcOH}$ & 451 & $0(77) 5$ & $3(52) 44$ & \\
\hline
\end{tabular}

$\mathrm{D} / \mathrm{A}=8(\mathrm{~mol} / \mathrm{mol})$

${ }^{\mathrm{a}} \mathrm{x}(\mathrm{y}) \mathrm{z}=$ yields of ethyl mandelate $\left(\mathbf{5}^{\prime}\right)$ (2-alkyl benzoylformate $(\mathbf{5 a}, \mathbf{5 b}$ or $\left.\mathbf{5 c})\right)$ 2-alkyl mandelate $\left(\mathbf{5} \mathbf{a}^{\prime}\right.$, $\mathbf{5} \mathbf{b}^{\prime}$ or $\mathbf{5} \mathbf{c}^{\prime}$ ), respectively

Table 4 Liquid phase transfer hydrogenation of 2-propyl benzoylpropionate (6) with secondary alcohols in the presence of $\mathrm{MgO}$

\begin{tabular}{|c|c|c|c|c|c|}
\hline \multirow[t]{2}{*}{ Donor } & \multirow[t]{2}{*}{$\mathrm{D} / \mathrm{A}$} & \multirow[t]{2}{*}{$\mathrm{T}_{\mathrm{r}}(\mathrm{K})$} & \multicolumn{3}{|c|}{ Yield of product ${ }^{\mathrm{a}}(\%) /$ Time (h) } \\
\hline & & & 1 & 3 & 6 \\
\hline 2-PrOH & 8 & 355 & 0 & 1 & 3 \\
\hline \multirow[t]{3}{*}{ 2-PeOH } & 4 & 392 & 4 & 10 & 23 \\
\hline & 8 & & 5 & 13 & 29 \\
\hline & 16 & & 2 & 7 & 16 \\
\hline \multirow[t]{3}{*}{$2-\mathrm{OcOH}$} & 4 & 451 & 12 & 27 & 42 \\
\hline & 8 & & 22 & 45 & 64 \\
\hline & 16 & & 5 & 10 & 31 \\
\hline
\end{tabular}

a 5-phenyl- $\gamma$-butyrolactone (5-Ph-GVL)<smiles>CCOC(=O)C(=O)c1ccccc1</smiles>

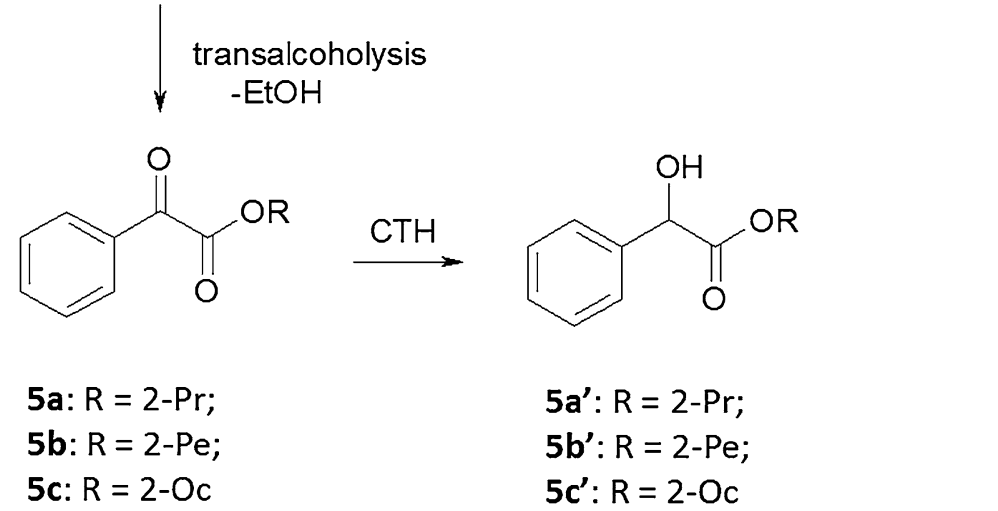

Scheme 7 Transformations of ethyl benzoylformate 
<smiles>[R]OC(=O)CCC(=O)c1ccccc1</smiles><smiles>[R]OC(=O)CCC(O)c1ccccc1</smiles><smiles>O=C1CCC(c2ccccc2)O1</smiles>
$6: R=2-P r ;$
$6^{\prime}: \mathrm{R}=2-\mathrm{Pr} ;$
6a: $R=E t$;
6a': $\mathrm{R}=\mathrm{Et}$;
$6 \mathrm{~b}: \mathrm{R}=n-\mathrm{Bu}$;
6b': $\mathrm{R}=n-\mathrm{Bu}$;
6c: $R=2-O c$
$6 c^{\prime}: R=2-O c$

\section{5-Ph-GVL}

Scheme 8 Formation of 5-phenyl- $\gamma$-valerolactone (5-Ph-GVL)

Yield of:

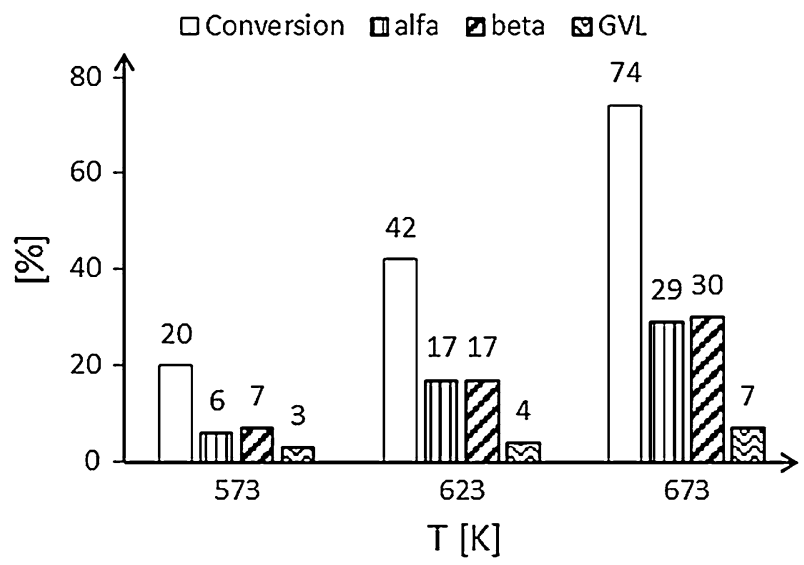

Fig. 5 Vapor phase CTH of 2-propyl levulinate with alcohols in the presence of $\mathrm{MgO}$. ( $\alpha$ - and $\beta$ angelica lactones, and GVL were observed among the reaction products)

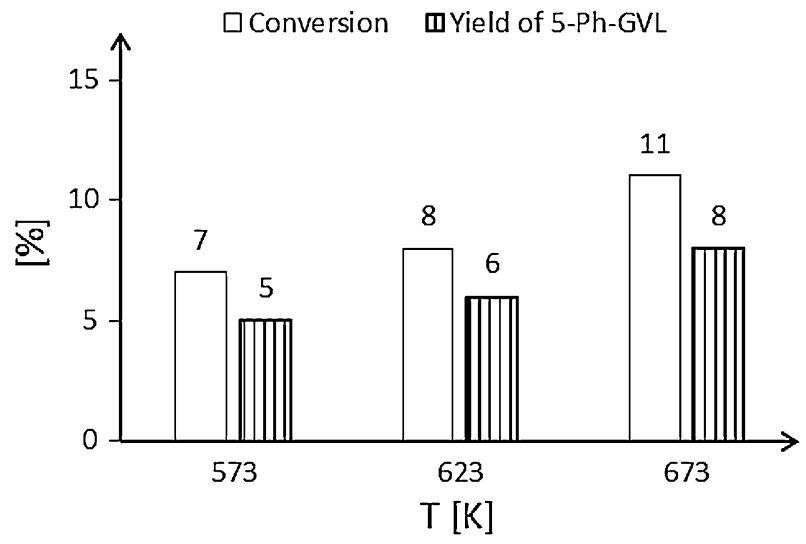

Fig. 6 Vapor phase CTH of 2-propyl benzoylpropionate with alcohols in the presence of $\mathrm{MgO}$ 


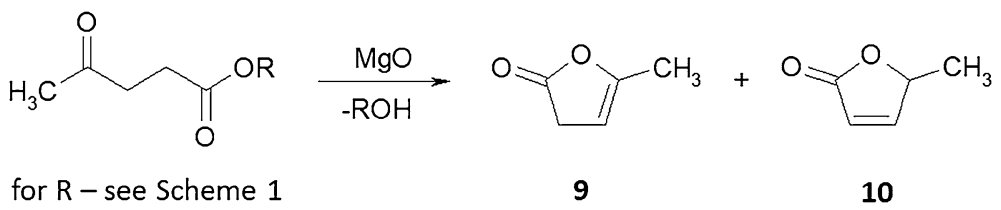

Scheme 9 Formation of $\alpha$ - (9) and $\beta$-angelica (10) lactones

Table 5 Results of comparable studies on liquid phase transfer hydrogenation of ketoesters and ketones with 2-pentanol in the presence of $\mathrm{MgO} . \mathrm{T}_{\mathrm{R}}=392 \mathrm{~K}, \mathrm{D} / \mathrm{A}=8(\mathrm{~mol} / \mathrm{mol})$

\begin{tabular}{llrc}
\hline Acceptor & \multicolumn{2}{l}{ Yield of product $(\%) /$ Time $(\mathrm{h})$} & 6 \\
\cline { 2 - 4 } & 1 & 3 & 84 \\
\hline $\mathbf{8}$ & $68^{\mathrm{a}}$ & 83 & $0^{\text {cd }}$ \\
$\mathbf{4}$ & $0^{\mathrm{b}}$ & 0 & 55 \\
$\mathbf{9}$ & $10^{\mathrm{e}}$ & 21 & 25 \\
$\mathbf{5}$ & $2^{\mathrm{f}}$ & 16 & \\
\hline
\end{tabular}

a 2-undecanol

b 2-propyl 6-hydroxoheptanoate

c $2 \%$ yield of 2-pentyl 6-oxoheptanoate was noted

${ }^{\mathrm{d}}$ At $451 \mathrm{~K}$ with 2-octanol as hydrogen donor $7 \%$ yield of 2-propyl 6-hydroxoheptanoate was noted

e 1-phenyl-1-pentanol

f Sum of ethyl and 2-pentyl mandelates

hydrogenation in the presence of $\mathrm{MgO}$ as the catalyst. As the representatives of the above-mentioned ketones, 2-undecanone (7) and valerophenone (8) were chosen (Table 5).

Aliphatic ketoester did not show any reactivity in CTH with 2-pentanol at $392 \mathrm{~K}$ in the presence of $\mathrm{MgO}$. Very low reactivity (7\%) was observed at a much higher temperature $(451 \mathrm{~K})$ with 2-octanol. It has been expected that for 2-propyl 6-oxoheptanoate (4), in which the carbonyl and carboxyl groups are separated by four carbon atoms, the reactivity of the carbonyl would not be influenced by the second group. Contrary to this, for the ketoester, such a big distance was deeply insufficient to preserve the high reactivity which is exhibited by simple aliphatic ketones. However, in a set containing a phenyl substituent, the ketoester (5) was also less reactive than the aralkyl ketone (9), but the difference between their reactivities was not as big as in the aliphatic set. In other words, the presence of the phenyl substituent in the ketoester molecule enables the preservation of its reactivity in CTH despite the strong deactivation caused by the carboxyl group.

\section{Conclusions}

The results of this thorough investigation show that an increase in the temperature or the time of the reaction increases the yield of the desired product. Moreover, the increase of the donor/acceptor ratio also has a positive effect of the GVL yield. In 
general, the reactivity of various ketoesters in CTH in liquid phase is much lower than the reactivity shown in CTH by aliphatic or aralkyl ketones. Even for 2-propyl 6-oxoheptanoate, in which the carbonyl and carboxyl groups are separated by four carbon atoms, the reactivity of the carbonyl group is greatly influenced by the latter group. It has also been found that the presence of a phenyl substituent in the molecule of a ketoester enhances its reactivity. It was found that the main side reaction is the transalcoholysis of ketoesters caused by the alcohols used as hydrogen donors. The products of this reaction were not observed only in the case of the ketoesters possessing the carbonyl group in the $\gamma$ position. Thus formed hydroxoesters undergo cyclization with the formation of lactones. Although the vapor phase mode of reaction has been performed at higher temperatures $(573-673 \mathrm{~K})$ than the liquid phase $(355-451 \mathrm{~K})$ it did not lead to any increase of the yield of the desired products.

Open Access This article is distributed under the terms of the Creative Commons Attribution License which permits any use, distribution, and reproduction in any medium, provided the original author(s) and the source are credited.

\section{References}

1. Ruiz JR, Sanchidrián CJ (2007) Curr Org Chem 11:1113-1125

2. Chuah GK, Jaenicke S, Zhu YZ, Liu SH (2006) Curr Org Chem 10:1639-1654

3. Szölösi G, Bartok M (1998) Appl Catal A Gen 169:263-269

4. Gliński M (2008) Appl Catal A Gen 349:133-139

5. Gliński M (2009) React Kinet Catal Lett 97:275-279

6. Gliński M (2010) Reac Kinet Mech Cat 99:93-98

7. Posner GH, Runquist AW, Chapdelaine MJ (1977) J Org Chem 42:1202-1208

8. Matsushita H, Ishiguro S, Ichinose H (1985) Chem Lett 14:731-734

9. Shibagaki M, Takahashi K, Matsushita H (1988) Bull Chem Soc Jpn 61:3283-3288

10. Liu SH, Jaenicke S, Chuah GK (2002) J Catal 206:321-330

11. Ruiz JR, Jimenez-Sanchidrián C, Hidalgo JM, Marinas JM (2006) J Mol Catal A 246:190-194

12. Aramendia MA, Borau V, Jimenez C, Marinas JM, Ruiz JR, Urbano FJ (2002) J Chem Soc Perkin Trans 2(6): 1122-1125

13. Aramendia MA, Borau V, Jimenez C, Marinas JM, Ruiz JR, Urbano FJ (2003) Appl Catal A Gen 255:301-308

14. Jimenez-Sanchidrián C, Hidalgo JM, Ruiz JR (2006) Appl Catal A Gen 303:23-28

15. Aramendia MA, Borau V, Jimenez C, Marinas JM, Romero FJ (1999) Catal Lett 58:53-58

16. Zhu Y, Chuah G, Jaenicke S (2004) J Catal 227:1-10

17. Corma A, Domine ME, Nemeth L, Valencia S (2002) J Am Chem Soc 124:3194-3195

18. Corma A, Domine ME, Valencia S (2003) J Catal 215:294-304

19. Kumbhar PS, Sánchez-Valente J, Lopez J, Figueras F (1998) Chem Commun 5:535

20. Aramendia MA, Borau V, Jimenez C, Marinas JM, Ruiz JR, Urbano FJ (2001) Appl Catal A Gen 206:95-101

21. Jyothi TM, Raja T, Rao BS (2001) J Mol Catal A 168:187-191

22. Gliński M, Gadomska A (1998) React Kinet Catal Lett 65:121-129

23. Gliński M (2009) Polish J Chem 83:187-194

24. Gliński M (2001) Polish J Chem 75:1059-1061

25. Johnstone RAW, Wilby AH, Entwistle ID (1985) Chem Rev 85:129-170

26. Di Cosimo JI, Acosta A, Apesteguia CR (2005) J Mol Catal A 234:111-120

27. Ueshima M, Shimasaki Y (1992) Chem Lett 21:1345-1348

28. Gliński M, Ulkowska U (2011) Catal Lett 141:293-299

29. Blaser H-U, Jallet HP, Múller M, Studer M (1997) Catal Today 37:441-463

30. Búrgi T, Baiker A (2004) Acc Chem Res 37:909-917 
31. Alonso DM, Wettstein SG, Bond JQ, Root TW, Dumesic JA (2011) ChemSusChem 4:1078-1081

32. Du X-L, He L, Zhao S, Liu Y-M, Cao Y, He H-Y, Fan K-N (2011) Angew Chem 123:7961-7965

33. Chia M, Dumesic JA (2011) Chem Commun 47:12233-12235

34. Danelska A, Ulkowska U, Socha RP, Szafran M (2013) J Eur Ceram Soc 33:1875-1883

35. Schaeffer JR, Snoddy AO (1963) Org Synth Coll 4:19-21

36. Sommerville LF, Allen CFH (1943) Org Synth Coll 2:81-83

37. Tanabe K, Misono M, Ono Y, Hattori H (1989) Stud Surf Sci Catal 51:27-213 